\title{
Tracheo-esophageal fistula following spontaneous migration of a missed impacted denture
}

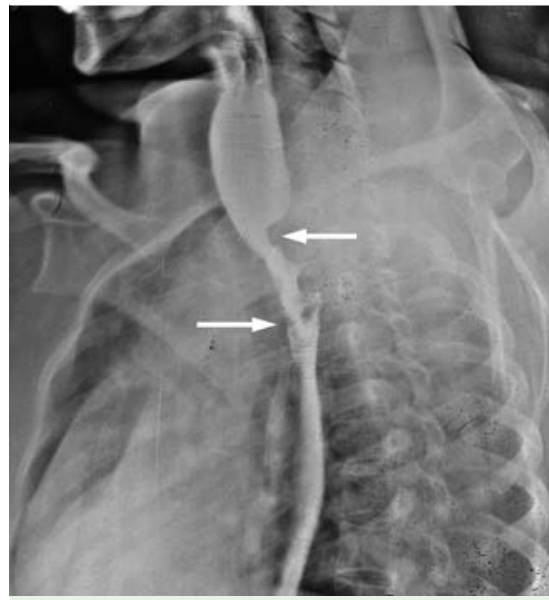

Fig. 1 A 50-year-old woman had dysphagia and cough when she drank liquids. A barium esophagogram from 3 years earlier showed a narrowed esophagus with mucosal irregularity (arrows).

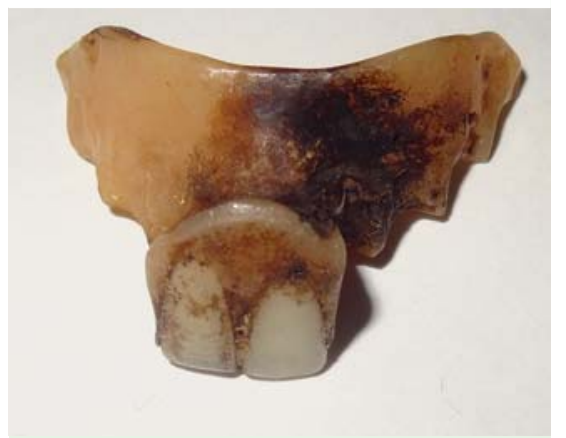

Fig. 2 The denture retrieved from the stool.

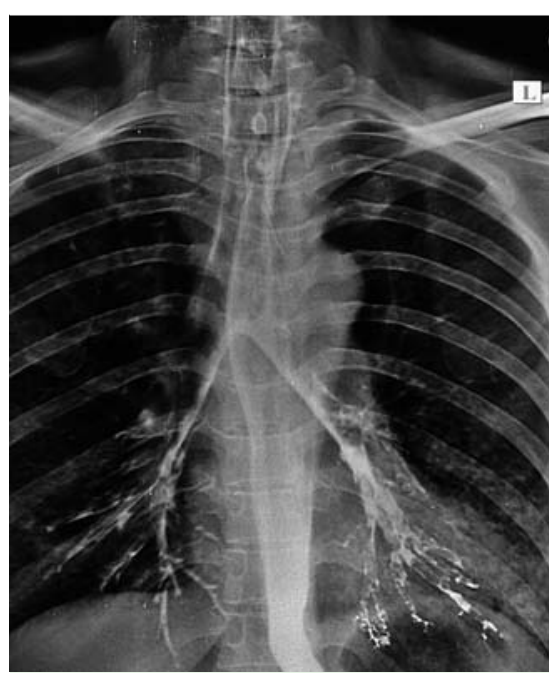

Fig.3 Contrast study of the esophagus shows a tracheo-esophageal fistula, with contrast outlining the tracheobronchial tree.
A 50-year-old woman presented with dysphagia and cough that occurred while she drank liquids. She had been treated elsewhere with endoscopic bougie dilation for mechanical dysphagia 3 years earlier. Barium esophagography at that time showed narrowing of the upper thoracic esophagus with mucosal irregularity ( $\boldsymbol{\bullet}$ Fig.1). Endoscopy revealed luminal narrowing, but multiple endoscopic biopsies as well as computed tomography of the chest did not reveal any specific pathology. She remained asymptomatic for 3 years following the dilation procedure.

The patient denied any history of corrosive ingestion, fever, recurrent pneumonia, or pulmonary tuberculosis. She also reported the spontaneous expulsion of a swallowed missing denture in her stool a day after the onset of her current symptoms ( $\bullet$ Fig. 2). She had accidentally swallowed this denture 4 years earlier. A contrast study of the esophagus revealed a tracheo-esophageal fistula (TEF), with contrast outlining the tracheobronchial tree ( $\bullet$ Fig. 3). Gastroscopy revealed luminal narrowing with multiple openings due to a mucosal bridge in the esophagus ( $\mathrm{Fig} .4$ ), and the opening of the TEF was also noted ( $\bullet$ Fig.5). An endoscope was negotiated into the lower esophagus over a guidewire, and a nasogastric tube was placed for feeding. The patient was then referred to surgery services for definitive management.

TEF is a rare but devastating complication of various benign and malignant diseases and can be congenital or acquired [1]. It is a known complication of foreign body impaction in the esophagus. Various types of foreign bodies, including dentures, can cause TEF, and the presentation is usually acute. Diagnosing impacted foreign bodies, especially radiolucent ones, in a late phase may be difficult. Impacted radiolucent dentures have been reported to be missed on imaging [2-4]. This case highlights the importance of the recognition and early retrieval of a foreign body after ingestion so as to prevent devastating complications.

\section{Endoscopy_UCTN_Code_CCL_1AB_2AF}

Competing interests: None

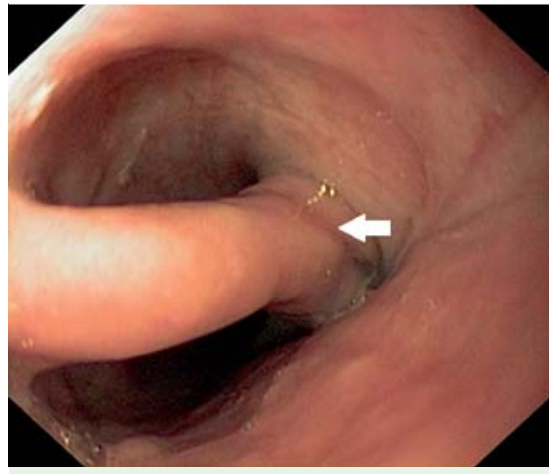

Fig.4 Endoscopy shows multiple openings due to a mucosal bridge (arrow).

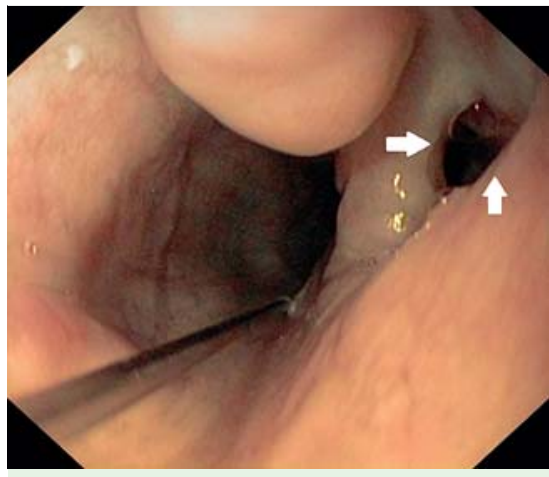

Fig. 5 During endoscopy, a guidewire is negotiated into the lower esophagus. The tracheoesophageal fistula opening is noted (arrows).

\section{Deepak Gunjan', Surinder S. Rana', Rajesh Gupta², Deepak K. Bhasin ${ }^{1}$}

${ }^{1}$ Department of Gastroenterology, Post Graduate Institute of Medical Education and Research (PGIMER), Chandigarh, India

2 Department of Surgery, Post Graduate Institute of Medical Education and Research (PGIMER), Chandigarh, India 


\section{References}

1 Reed MF, Mathisen DJ. Tracheoesophageal fistula. Chest Surg Clin N Am 2003; 13: 271-289

2 Deshpande G, Samarasam I, Banerjee S et al. Benign esophagorespiratory fistula: a case series and a novel technique of definitive management. Dis Esophagus 2013; 26: $141-147$

3 Firth AL, Moor J, Goodyear PW et al. Dentures may be radiolucent. Emerg Med J 2003; 20: $562-563$

4 Samarasam I, Chandran S, Shukla V et al. A missing denture's misadventure! Dis Esophagus 2006; 19: $53-55$

\section{Bibliography}

Dol http://dx.doi.org/

10.1055/s-0034-1392326

Endoscopy 2015; 47: E331-E332

(C) Georg Thieme Verlag KG

Stuttgart · New York

ISSN 0013-726X

\section{Corresponding author}

Surinder Singh Rana, MD

Department of Gastroenterology

Postgraduate Institute of Medical Education and Research (PGIMER)

Chandigarh

India 160012

Fax: +91-172-2744401

drsurinderrana@yahoo.co.in 